\title{
State laws on youth access to tobacco in the United States: measuring their extensiveness with a new rating system
}

\author{
Marianne H Alciati, Marcy Frosh, Sylvan B Green, Ross C Brownson, Peter H Fisher, \\ Robin Hobart, Adele Roman, Russell C Sciandra, Dana M Shelton
}

Management Solutions
for Health, Reston,
Virginia, USA
M H Alciati
The MayaTech
Corporation, Silver
Spring, Maryland
M Frosh
Department of
Epidemiology and
Biostatistics, School of
Medicine, Case
Western Reserve
University, Cleveland,
Ohio
S B Green

S B Green

Department of Community Health and Prevention Research Center, School of Public Health, St Louis University, St Louis, Missouri

R C Brownson

National Center for Tobacco-free Kids, Washington, DC P H Fisher

Americans for Nonsmokers' Rights, Berkeley, California R Hobart

Center for Substance Abuse Prevention, Substance Abuse and Mental Health

Services

Administration, Rockville, Maryland A Roman

Stottville, New York R C Sciandra

Office on Smoking and Health, National Center for Chronic Disease Prevention and Health Promotion, US Centers for Disease Control and

Prevention, Atlanta, Georgia

D M Shelton

Correspondence to: Correspondence to: Edge Lane, Reston, Virginia 20190, USA malciati@erols.com

\begin{abstract}
Objective-To develop and implement a rating system evaluating the extensiveness of state laws restricting youth access to tobacco.

Design-State laws on youth access to tobacco were analysed and assigned ratings on nine items. Six items addressed specific tobacco-control provisions, and three related to enforcement provisions. For each item, a target was specified reflecting public health objectives. Achieving the target resulted in a rating of +4 points; for three items, a rating of +5 was possible if the target was exceeded. Criteria for lower ratings were established for situations when the target was not met. Setting-United States.

Results-State scores (sum of the ratings across all nine items) ranged from 0-18 in 1993, 2-21 in 1994, and 1-21 in 1995 and 1996, out of a possible total of 39 . The average score across states was 7.2 in 1993, 7.9 in 1994, 8.2 in 1995, and 9.0 in 1996. The overall mean rating (per item) was 0.80 in $1993,0.88$ in $1994,0.91$ in 1995 , and 1.00 in 1996, on a scale where 4.0 indicates that the target goals (per item) were met. From 1993 to 1996, scores increased for 20 states, decreased for one state, and remained unchanged for the others. The number of states for which state preemption of local tobacco regulation was a factor doubled from 10 states in 1993 to 20 states in 1996. Conclusions-Although all states have laws addressing youth access to tobacco, this analysis reveals that, as of the end of 1996, the progress towards meeting health policy targets is slow, and state legislation that preempts local tobacco regulation is becoming more common.

(Tobacco Control 1998;7:345-352)
\end{abstract}

Keywords: adolescents, legislation, access laws, United States

\section{Introduction}

The significant adverse health effects of cigarette smoking are well documented. Smoking has been associated with at least nine major sites of cancer, ${ }^{1}$ coronary heart disease, stroke and other cardiovascular disease, and chronic obstructive pulmonary disease. ${ }^{2}$ Smoking accounts for about one in five deaths annually in the United States. ${ }^{3}$

Tobacco use among young people is an important public health problem. Daily cigarette use among high school seniors declined sharply in the 1970s and early 1980s. ${ }^{45}$ However, recent estimates indicate that the percentage of those in grades 8 (ages 13-14), 10 (ages 15-16), and 12 (ages 17-18) who smoke cigarettes daily increased from 1991 to $1996 .{ }^{6}$ Daily smoking was reported in 1996 by $22.2 \%$ of 12 th-graders, $18.3 \%$ of 10th-graders, and $10.4 \%$ of 8 th-graders. ${ }^{6}$ Smoking begins principally in childhood and adolescence. ${ }^{7}$ Even if young people begin smoking believing that they will be able to stop, ${ }^{7}$ addiction to nicotine in cigarettes makes stopping smoking difficult, and initiation of tobacco use among young people often starts a lifelong, and life-threatening, behaviour. ${ }^{8}{ }^{9}$

Among the primary mechanisms currently being used to address the public health problem of tobacco use in the United States is policy. Policy plays a central role in addressing environmental and social factors proven to contribute to the initiation and maintenance of tobacco use. ${ }^{2710-12}$ Addressing the specific issue of tobacco use among young people, numerous state laws have been enacted to restrict youth access to tobacco. ${ }^{13}$ Scientific evidence has been gathered to support the potential of well-enforced laws to reduce youth access to tobacco by preventing the sale of tobacco products to minors, ${ }^{14}{ }^{15}$ although another recent study concluded that enforcing tobacco control laws may not reduce youth access to, or use of, cigarettes. ${ }^{16}$

This paper describes the development and implementation of a rating system to evaluate the extensiveness of state laws on youth access to tobacco. This effort was based on the National Cancer Institute's (NCI's) State Cancer Legislative Database (SCLD) programme, the youth-access policy guidelines developed by the American Stop Smoking Intervention Study (ASSIST), and consensus by a technical advisory committee established for this project.

The SCLD programme has monitored state cancer-related legislation since the early 1980s and has maintained a database of such legislation since 1989. The SCLD database provides for the rapid identification of laws that contain provisions addressing specific issues, and a 
Table 1 Targets for each item in the youth access score

\begin{tabular}{lll}
\hline Item & Target \\
\hline $1 \quad$ Minimum age & $\begin{array}{l}\text { Prohibits the sale or distribution of any tobacco products to persons under 18 years of age } \\
\text { through any sales or distribution outlet, and a warning sign is required at point of purchase with } \\
\text { specific penalty for failing to post a sign. }\end{array}$ \\
2 Packaging & $\begin{array}{l}\text { Prohibits all cigarette sales other than in a sealed package conforming to federal labelling } \\
\text { requirements. }\end{array}$ \\
3 & Prohibits access to or purchase of tobacco products without the intervention of a sales clerk. \\
4 & Photo identification & $\begin{array}{l}\text { Requires merchants to request photographic identification for customers who appear to be } \\
\text { under } 21 \text { years of age. }\end{array}$ \\
5 & Vending machines & $\begin{array}{l}\text { Total ban on sale of all tobacco products through vending machines in all locations. } \\
\text { Total ban on distribution of free tobacco samples, coupons for free samples, or rebates. }\end{array}$ \\
7 & Free distribution & $\begin{array}{l}\text { Establishes a system of graduated penalties or fines applicable to all youth access laws, to be } \\
\text { levied within three years, plus possibility of suspension or revocation of a required tobacco retail }\end{array}$ \\
8 & Random inspections & $\begin{array}{l}\text { licence for repeated sales to minors. } \\
\text { Establishes random, unannounced inspections of retailers as part of the enforcement } \\
\text { mechanism, using underage buyers for the purpose of identifying violators, and does not } \\
\text { prohibit other use of minors to test compliance. } \\
\text { Establishes a clearly designated statewide enforcement authority for sales. }\end{array}$ \\
9 & Statewide enforcement &
\end{tabular}

description of the provisions within each state law. ASSIST is a collaborative effort between the NCI and the American Cancer Society, along with state and local health departments and other voluntary organisations. It is a demonstration project implemented in 17 states to develop comprehensive programmes for prevention and control of tobacco use. ASSIST policy guidelines on youth access to tobacco were developed to provide information on tobacco control initiatives to these 17 ASSIST states. These guidelines provide policy options most likely to reduce youth access to tobacco, and they identify "loopholes"-provisions in state legislation that may limit the potential effect of youth access laws.

Building on the strengths of these initiatives, the present analysis sought to take a closer look at state-mandated policies on youth access to tobacco, by generating quantitative information on state laws based on a qualitative evaluation of the potential public health impact of specific provisions within these laws. By comparing searchable SCLD data on state laws with policy options identified by ASSIST, a technical advisory committee (comprised of the authors of this paper) developed a rating system for state laws that target youth access to tobacco products. This effort breaks new ground in characterising the extensiveness of these laws in the context of desired public health policies.

An important goal of this ratings project is to develop methodology that would be available as a model for a variety of cancer control applications at multiple levels of policy making. In the area of tobacco control, separate ratings are planned for clean indoor air and potentially other tobacco control topics. These can then be combined in an overall summary rating. This paper reports specifically on youth access to tobacco.

\section{Methods}

DEVELOPING RATINGS CRITERIA

The objective was to develop a rating system and assign ratings for laws on youth access to tobacco in each state (the 50 states and the District of Columbia, (hereafter called "the states")). Ratings were determined for laws in effect at four time points: the end of 1993, 1994, 1995, and 1996. At any given time point, the total score for each state is the sum of the ratings on nine items (table 1 ), reflecting how closely state law approximated a series of nine target provisions that were identified as important to youth-access tobacco policy. Six of these address specific provisions to control access to tobacco products and three relate to enforcement provisions, thus dividing the total score into two separate components.

For each of the nine items, a "target" reflecting public health objectives for controlling youth access to tobacco was specified (table 1). Achieving the target on any given provision resulted in a rating of +4 points. For three items, it was possible to exceed the target and receive a rating of +5 (see Appendix). The interpretation of each possible rating is as follows.

$\begin{array}{rll}+5 & \text { Exceeds target } & \text { Outstanding } \\ +4 & \text { Meets target } & \text { Excellent } \\ +3 & \text { Meets } \sim 75 \% \text { of target } & \text { Good } \\ +2 & \text { Meets } \sim 50 \% \text { of target } & \text { Fair } \\ +1 & \text { Meets } \sim 25 \% \text { of target } & \text { Minimal } \\ 0 & \text { No effective provision } & \text { None }\end{array}$

For each item, criteria for assigning ratings at specific levels were established (see Appendix). As part of this process, it was necessary to define the effects on the rating of specific limitations or restrictions on individual provisions; for some items it was not possible to define ratings at all levels. For example, item 1 addressed the minimum age for sale or distribution of tobacco products. A rating of +4 was assigned to states that mandated a minimum age of 18 years, and a rating of +5 was possible if a state mandated a minimum age greater than 18 years. The rating on item 1 was only +3 if a state met the target age but did not require signs to be posted or there was no specific penalty for failure to post a sign.

Whenever there was state preemption of stricter local ordinances, the ratings were reduced by two points for each affected item (with the lowest possible item rating being 0 ). This reflects the view of the technical advisory committee that preemptive language is undesirable, even if a state has made a maximum effort on a particular youth access topic. ${ }^{17}$ Numerous public health organisations have stated their formal opposition to preemption of local initiatives in tobacco control ${ }^{18} 19$ and, as discussed below, local jurisdictions are 
Table 2 Youth access scores by state for 1993 through 1996

\begin{tabular}{|c|c|c|c|c|c|}
\hline State & $\begin{array}{l}1993 \\
\text { Score }\end{array}$ & $\begin{array}{l}1994 \\
\text { Score }\end{array}$ & 1995 Score & $\begin{array}{l}1996 \\
\text { Score }\end{array}$ & $\begin{array}{l}\text { Change from } \\
1993 \text { to } 1996\end{array}$ \\
\hline Alabama & 5 & 5 & 5 & 5 & 0 \\
\hline Alaska & 5 & 5 & 5 & 5 & 0 \\
\hline Arizona & 3 & 3 & 3 & 3 & 0 \\
\hline Arkansas & 10 & 10 & 10 & 10 & 0 \\
\hline California & $8(10)$ & $17(19)$ & $19(21)$ & $19(21)$ & 11 \\
\hline Colorado & 5 & 5 & 5 & 5 & 0 \\
\hline Connecticut & 18 & 18 & 18 & 20 & 2 \\
\hline Delaware & 3 & 3 & 3 & $9(21)$ & 6 \\
\hline District of Columbia & 12 & 12 & 12 & 12 & 0 \\
\hline Florida & 15 & 15 & 15 & 15 & 0 \\
\hline Georgia & 15 & 15 & 15 & 15 & 0 \\
\hline Hawaii & 8 & 8 & 8 & 13 & 5 \\
\hline Idaho & 5 & 5 & 5 & 5 & 0 \\
\hline Illinois & 8 & 8 & 9 & 9 & 1 \\
\hline Indiana & 5 & 5 & 5 & 5 & 0 \\
\hline Iowa & $3(11)$ & $3(11)$ & $3(11)$ & $3(11)$ & 0 \\
\hline Kansas & 5 & 5 & 5 & 14 & 9 \\
\hline Kentucky & 4 & $6(13)$ & $6(13)$ & $6(16)$ & 2 \\
\hline Louisiana & 4 & $8(10)$ & $8(10)$ & $8(10)$ & 4 \\
\hline Maine & 9 & 9 & 11 & 11 & 2 \\
\hline Maryland & 3 & 3 & 3 & 3 & 0 \\
\hline Massachusetts & 6 & 6 & 6 & 9 & 3 \\
\hline Michigan & $3(11)$ & $3(11)$ & $3(11)$ & $3(11)$ & 0 \\
\hline Minnesota & 8 & 8 & 8 & 8 & 0 \\
\hline Mississippi & 5 & $6(18)$ & $6(18)$ & $6(18)$ & 1 \\
\hline Missouri & 10 & 10 & 10 & 10 & 0 \\
\hline Montana & $3(10)$ & $3(10)$ & $7(20)$ & $7(20)$ & 4 \\
\hline Nebraska & 10 & 10 & 10 & 10 & 0 \\
\hline Nevada & 7 & 7 & 7 (15) & 7 (15) & 0 \\
\hline New Hampshire & 10 & 10 & 10 & 10 & 0 \\
\hline New Jersey & 6 & 6 & 6 & 12 & 6 \\
\hline New Mexico & $8(18)$ & $8(18)$ & $8(18)$ & $8(18)$ & 0 \\
\hline New York & $17(19)$ & $21(23)$ & $21(23)$ & $21(23)$ & 4 \\
\hline North Carolina & 3 & 3 & $1(6)$ & $1(6)$ & -2 \\
\hline North Dakota & 5 & 5 & 5 & 5 & 0 \\
\hline Ohio & 8 & 8 & 8 & 8 & 0 \\
\hline Oklahoma & 5 & $9(23)$ & $9(23)$ & $9(23)$ & 4 \\
\hline Oregon & $15(16)$ & $15(16)$ & $15(16)$ & $15(16)$ & 0 \\
\hline Pennsylvania & 6 & 6 & 6 & 6 & 0 \\
\hline Rhode Island & 8 & 8 & 8 & 18 & 10 \\
\hline South Carolina & 5 & 5 & 5 & $6(14)$ & 1 \\
\hline South Dakota & 3 & $3(13)$ & $3(13)$ & $3(13)$ & 0 \\
\hline Tennessee & 9 & $9(21)$ & $9(21)$ & $9(21)$ & 0 \\
\hline Texas & 7 & 7 & 7 & 7 & 0 \\
\hline Utah & 9 & 13 & 13 & 13 & 4 \\
\hline Vermont & 15 & 15 & 15 & 15 & 0 \\
\hline Virginia & 0 & 4 & 8 & 11 & 11 \\
\hline Washington & $10(26)$ & $10(26)$ & $10(26)$ & $10(26)$ & 0 \\
\hline West Virginia & 6 & 12 & 12 & 12 & 6 \\
\hline Wisconsin & $2(5)$ & $2(5)$ & $2(5)$ & $2(5)$ & 0 \\
\hline Wyoming & $5(7)$ & $5(7)$ & $5(7)$ & $5(7)$ & 0 \\
\hline
\end{tabular}

^Scores before preemption penalties are shown in parentheses.

well-suited to the development of practical new policy solutions to curb tobacco use by minors, particularly when states fail to enact or enforce their own provisions.

CODING LAWS TO ACHIEVE INDIVIDUAL RATINGS SCLD abstracts of laws on youth access were reviewed and two raters each developed initial ratings for the years 1993 through 1996. These initial ratings were then compared and coded to form a final consensus rating. To assess the extent to which independent raters are consistent in coding the laws, a third rater-who had not previously abstracted or analysed youth access laws-reviewed the SCLD abstracts for all states for the baseline year (1993), and created independent ratings. The overall inter-rater agreement for the measure was $92 \%$. Higher agreement rates were found for four of the nine provisions related to out-of-package sales, clerk intervention, identification requirements, and inspections. Lower agreement rates (between $82 \%$ and $86 \%$ ) were found for the provisions related to vending machines, penalties, and enforcement.
Results

The rating system was applied to enacted youth access legislation from each of the states. Table 2 shows the scores for all 51 states for the years 1993-1996, as well as the difference between 1993 and 1996. A state that met all nine targets for controlling youth access to tobacco would have scored 36 points (and a total of 39 possible points if it exceeded the target on each of the three items for which that was possible). The actual ranges were $0-18$ for 1993, 2-21 for 1994, and 1-21 for 1995 and 1996. From 1993 through 1996, the scores increased for 20 states, decreased for one state, and remained unchanged for the others. The average score across states was 7.2 in 1993, 7.9 in $1994,8.2$ in 1995, and 9.0 in 1996. The overall mean rating (per item) was 0.80 in $1993,0.88$ in $1994,0.91$ in 1995 , and 1.00 in 1996 , on a scale where 4.0 would indicate that target goals (per item) were met. Most states (39 states in 1993, 36 states in 1994, 35 states in 1995, and 30 states in 1996) had total scores of nine or less, equivalent to a mean item rating less than or equal to 1.0 (or "minimal", using the interpretation that is applied for the 0 to +5 point structure).

Table 3 shows the frequency of individual ratings ( $0-5$ points) for each of the nine items. Looking at separate components, mean ratings for specific tobacco-control provisions (items $1-6)$ were 0.76 in $1993,0.78$ in $1994,0.81$ in 1995, and 0.88 in 1996; mean ratings for enforcement provisions (items 7-9) were 0.88 in $1993,1.08$ in $1994,1.10$ in 1995 , and 1.26 in 1996.

The number of states for which a preemption penalty was applied doubled from 10 states in 1993 to 20 states in 1996. The number of times for which there was a preemption penalty for each particular item is shown in table 4.

Of the nine items, the highest ratings were for item 1: minimum age (table 3). By 1994, all states had passed laws prohibiting cigarette sales or distribution to minors. A number of states received a rating of +3 because they met the 18-year minimum age but not the signage requirements (that is, including a specific penalty for failure to post a sign). Other states lost points because of preemption language-for example, their laws prohibited local governments from raising the minimum age.

Conversely, the lowest ratings were for item 3: clerk intervention. Self-service displays can make tobacco purchases appealing and accessible to shoplifting; several surveys indicate that up to a half of student smokers interviewed reported that they have shoplifted cigarettes. ${ }^{20}$ There is evidence that self-service displays may result in higher purchase success rates among underage buyers. ${ }^{21}$ Nevertheless, as of 1996, no state had prohibited or restricted self-service displays by state law.

For three of the nine items, it was possible to exceed the target and achieve a rating of +5 . Across all years, there was only one instance of such a rating: New York received +5 for item 4 , by requiring photo identification for 
Table 3 Frequency of individual youth access ratings for 1993 through 1996

\begin{tabular}{|c|c|c|c|c|c|c|c|c|}
\hline \multirow{2}{*}{\multicolumn{2}{|c|}{ Item }} & \multicolumn{7}{|c|}{1993 Rating } \\
\hline & & 0 & 1 & 2 & 3 & 4 & 5 & Mean \\
\hline 1 & Minimum age & 1 & 2 & 6 & 22 & 20 & 0 & 3.1 \\
\hline 2 & Packaging & 42 & 1 & 3 & 3 & 2 & & 0.5 \\
\hline 3 & Clerk identification & 51 & 0 & 0 & 0 & 0 & & 0.0 \\
\hline 4 & Photo identification & 44 & 3 & 2 & 1 & 0 & 1 & 0.3 \\
\hline 5 & Vending machines & 34 & 12 & 5 & 0 & 0 & & 0.4 \\
\hline 6 & Free distribution & 44 & 3 & 4 & 0 & 0 & 0 & 0.2 \\
\hline 7 & Graduated penalties & 22 & 0 & 15 & 7 & 7 & & 1.5 \\
\hline 8 & Random inspections & 45 & 0 & 4 & 0 & 2 & & 0.3 \\
\hline \multirow{2}{*}{\multicolumn{2}{|c|}{9 Statewide enforcement }} & 38 & 0 & 6 & 0 & 7 & & 0.8 \\
\hline & & \multicolumn{7}{|c|}{1994 Rating } \\
\hline \multicolumn{2}{|c|}{ Item } & 0 & 1 & 2 & 3 & 4 & 5 & Mean \\
\hline 1 & Minimum age & 0 & 3 & 11 & 19 & 18 & 0 & 3.0 \\
\hline 2 & Packaging & 37 & 1 & 7 & 3 & 3 & & 0.7 \\
\hline 3 & Clerk identification & 51 & 0 & 0 & 0 & 0 & & 0.0 \\
\hline 4 & Photo identification & 42 & 5 & 2 & 1 & 0 & 1 & 0.3 \\
\hline 5 & Vending machines & 34 & 12 & 5 & 0 & 0 & & 0.4 \\
\hline 6 & Free distribution & 44 & 3 & 4 & 0 & 0 & 0 & 0.2 \\
\hline 7 & Graduated penalties & 25 & 0 & 13 & 7 & 6 & & 1.4 \\
\hline 8 & Random inspections & 38 & 0 & 10 & 0 & 3 & & 0.6 \\
\hline \multirow{2}{*}{\multicolumn{2}{|c|}{9 Statewide enforcement }} & 30 & 0 & 11 & 0 & 10 & & 1.2 \\
\hline & & \multicolumn{7}{|c|}{1995 Rating } \\
\hline \multicolumn{2}{|c|}{ Item } & 0 & 1 & 2 & 3 & 4 & 5 & Mean \\
\hline 1 & Minimum age & 0 & 5 & 11 & 17 & 18 & 0 & 2.9 \\
\hline 2 & Packaging & 35 & 1 & 8 & 3 & 4 & & 0.8 \\
\hline 3 & Clerk identification & 51 & 0 & 0 & 0 & 0 & & 0.0 \\
\hline 4 & Photo identification & 42 & 5 & 2 & 1 & 0 & 1 & 0.3 \\
\hline 5 & Vending machines & 30 & 15 & 6 & 0 & 0 & & 0.5 \\
\hline 6 & Free distribution & 44 & 3 & 4 & 0 & 0 & 0 & 0.2 \\
\hline 7 & Graduated penalties & 25 & 0 & 14 & 7 & 5 & & 1.4 \\
\hline 8 & Random inspections & 37 & 0 & 11 & 0 & 3 & & 0.7 \\
\hline \multirow{2}{*}{\multicolumn{2}{|c|}{9 Statewide enforcement }} & 28 & 0 & 13 & 0 & 10 & & 1.3 \\
\hline & & \multicolumn{7}{|c|}{1996 Rating } \\
\hline \multicolumn{2}{|c|}{ Item } & 0 & 1 & 2 & 3 & 4 & 5 & Mean \\
\hline 1 & Minimum age & 0 & 6 & 12 & 14 & 19 & 0 & 2.9 \\
\hline 2 & Packaging & 31 & 1 & 9 & 3 & 7 & & 1.1 \\
\hline 3 & Clerk identification & 51 & 0 & 0 & 0 & 0 & & 0.0 \\
\hline 4 & Photo identification & 41 & 5 & 2 & 2 & 0 & 1 & 0.4 \\
\hline 5 & Vending machines & 28 & 16 & 7 & 0 & 0 & & 0.6 \\
\hline 6 & Free distribution & 41 & 6 & 4 & 0 & 0 & 0 & 0.3 \\
\hline 7 & Graduated penalties & 25 & 1 & 13 & 6 & 6 & & 1.4 \\
\hline 8 & Random inspections & 33 & 0 & 15 & 0 & 3 & & 0.8 \\
\hline 9 & Statewide enforcement & 23 & 0 & 15 & 0 & 13 & & 1.6 \\
\hline
\end{tabular}

persons who appear to be under 25 years of age (table 3).

\section{Discussion}

Despite the existence of at least a minimum-age law for the sale and distribution of tobacco products in every state, young people are readily able to purchase or otherwise obtain cigarettes, and smoking prevalence in this age category is not decreasing. ${ }^{22}{ }^{23}$ This would suggest the potential importance of a multifaceted approach to reduce youth access to tobacco, such as the nine items in this rating

Table 4 Number of states with preemption penalties in youth access ratings for 1993-1996

\begin{tabular}{|c|c|c|c|c|c|}
\hline \multicolumn{2}{|c|}{ Item } & \multirow{2}{*}{$\begin{array}{c}1993 \\
8\end{array}$} & \multirow{2}{*}{$\begin{array}{l}1994 \\
14\end{array}$} & \multirow{2}{*}{$\begin{array}{l}1995 \\
16\end{array}$} & \multirow{2}{*}{$\begin{array}{l}1996 \\
18\end{array}$} \\
\hline 1 & Minimum age & & & & \\
\hline 2 & Packaging & 4 & 8 & 9 & 10 \\
\hline 3 & Clerk identification & 0 & 0 & 0 & 0 \\
\hline & Photo identification & 2 & 5 & 6 & 7 \\
\hline 5 & Vending machines & 7 & 12 & 12 & 13 \\
\hline 6 & Free distribution & 3 & 6 & 6 & 6 \\
\hline 7 & Graduated penalties & 2 & 4 & 5 & 8 \\
\hline 8 & Random inspections & 2 & 7 & 10 & 12 \\
\hline & Statewide enforcement & 4 & 9 & 11 & 13 \\
\hline \multicolumn{2}{|c|}{ Any item } & 10 & 16 & 18 & 20 \\
\hline
\end{tabular}

system (see table 1). Overall, this analysis found that youth access laws in 1993 through 1996 met very few targeted policy goals. Moreover, between 1993 and 1996, states moved increasingly to shut off local regulation of youth access to tobacco (state preemption) at a time when local initiatives had been shown to experience success. ${ }^{15}$ Thus, the overall mean rating was 0.80 in $1993,0.88$ in $1994,0.91$ in 1995 , and 1.00 in 1996, measured on a scale where a rating of 4.0 would indicate that the nine target goals (per item) were met. Even if no reductions had been taken because of preemption, the overall mean rating would have been only 0.93 in $1993,1.14$ in 1994 , 1.20 in 1995, and 1.35 in 1996.

COMPLEXITIES IN RATING STATE LAWS

State laws vary considerably in their scope and content. The lack of uniformity among the laws raised certain technical challenges in devising a rating system. Some items proved more difficult to rate than others. For example, ratings concerning vending machines were based on whether states specifically restricted vending machines to adult or mostly adult locations, or legislated other vending machine location restrictions, requirements for locking devices, or the like. Lack of supervision of the vending machine venue lowered states' ratings even if location restrictions were in place. The greatest difficulty in determining ratings occurred when state laws listed a series of alternative restrictions for placement, and certain of these restrictions were strict while others were quite relaxed. The result was that a state law that mandated certain aggressive features would nevertheless receive a lower rating if it also offered the option for less aggressive control of vending machines.

Evaluating provisions that addressed the free distribution of samples raised similar difficulties. Research shows that free samples end up in the hands of children; one study found that almost half of elementary and secondary school students reported seeing samples given to children. ${ }^{24}$ State laws in this area, as of 1996, focused principally on restricting locations at which sample distribution could occur; however, the laws did not take a uniform approach. Some of the more extensive sample-distribution provisions did not result in a high rating if the law contained significant exceptions (such as permitting sampling on private property), or contained preemption language.

The scheme of penalties for violations of minors' access laws also created rating difficulties. Many experts believe that the best approach to penalising offenders is to adopt graduated penalties which could result in license suspension/revocation. ${ }^{25}$ A few states, however, had hybrid laws in 1993-1996 that combined graduated and set penalties. Ratings for those states were not as high as ratings for states that had graduated penalties leading to possible licence suspension/revocation for all of their youth access laws.

Provisions that weakened the ability to enforce penalty schemes were particularly 
problematic. It is widely recognised that prosecution of tobacco sales to minors is given low priority by law enforcement officials. ${ }^{26}$ For example, laws that include an intent requirement - for example, requiring a "knowing" or "intentional" violation of the law-make prosecution extremely difficult. The technical advisory committee therefore determined that a state's rating should be "zeroed out" on this item if liability for illegal sales was very weak.

State requirements for random inspections increasingly allow the use of minors for compliance checks but restrict the participation of minors to inspections by one authority only. A careful look at states' inspection language is important to determine the extent to which the inspection provisions strengthen enforcement. Accordingly, states that limited the use of minors in compliance activities lost points in the ratings. It should be noted that state laws do not encompass all activity in this area of enforcement - a 1994 survey reported that some type of compliance activity, legislative or non-legislative, or random survey of tobacco vendors, had been undertaken in 44 states. $^{27}$

\section{THE ISSUE OF PREEMPTION}

State preemption of local policy initiatives posed a special technical challenge. Such preemption, advocated by the tobacco industry, is opposed by many public health professionals and associations. ${ }^{18} 1928-32$ The American Public Health Association's 1994 policy statement specifically opposed "state and Federal laws preempting local governments' ability and authority to enact their own more stringent restrictions on alcohol and tobacco availability." 19 Consistent with this, ratings were lowered by two points on individual items if preemption was present.

This approach followed considerable discussion among technical advisory committee members and reflects the significant, multifaceted power of preemption to weaken and limit states' overall policy approaches to addressing the problem of youth access to tobacco. ${ }^{17}$ First, by eliminating the potential for local jurisdictions to enact youth access ordinances, an important "testing ground" for youth access policy is eliminated. Second, local efforts often provide state officials with information about the costs and benefits of different policy approaches $^{33}$ and can provide valuable lessons about implementation and policy efficacy. ${ }^{28-32}$ Third, local debate about proposed ordinances provides a rich opportunity for community education about the consequences of tobacco use and the unique problems of youth access to tobacco. ${ }^{33}$ Finally, many states have found it difficult to repeal preemptive language in state tobacco control laws, and few, if any, have done so successfully. ${ }^{28-32}$ Thus, even if a state's current law meets the youth access target as defined in this rating system but includes preemption, future amendments that might weaken that state law or failure to enforce the state law cannot be addressed at the local level, thereby weakening the overall policy approach within a state.

\section{FEDERAL INITIATIVES}

An important catalyst for state legislation in 1993 and beyond was the Synar Amendment to the Public Health Service Act of $1992 .{ }^{34}$ As a condition for receiving certain block grants, this act requires states to provide evidence of enforcement of state laws setting a minimum age of 18 years for minors' access to tobacco, and requires states to conduct "random, unannounced inspections" of tobacco sellers.

Subsequent to the development of the ratings system described here, on 23 August 1996, President Clinton announced the publication of the US Food and Drug Administration's (FDA's) final rule on tobacco and youth. ${ }^{35}$ The validity of the FDA rule-making is currently being challenged in the case "Brown \& Williamson Tobacco Corp. v. Food and Drug Administration".

The FDA restrictions on youth access to tobacco are similar to the targets developed by the technical advisory committee for the state ratings here. Under the FDA rule, the sale of cigarettes and smokeless tobacco products to young people under 18 years of age is prohibited, retailers are required to check the photographic identification of anyone age 26 or younger, package size is a minimum of 20 cigarettes and retailers may not open packages, vending machines and self-service displays are restricted to adult-only locations, and mail-order redemption of coupons and distribution of free samples are prohibited. ${ }^{35}$

The FDA rule also includes provisions (not addressed in this rating system) affecting the format of advertising, sale and distribution of non-tobacco items and services, sponsorship of events, and public education. Under section 521(a) of the federal Food, Drug, and Cosmetic Act, state and local laws on the sale and distribution of cigarettes and smokeless tobacco products may be preempted; however, section $521(\mathrm{~b})$ permits exemptions to this preemption provision. ${ }^{35}$

\section{USES AND LIMITATIONS}

The rating system described here provides a numerical rating of the extensiveness of state laws on youth access to tobacco, measured against targets based on health policy goals. Such ratings can also be used to follow changes over time in state laws. The data presented here show changes from 1993 to 1996, and the SCLD database will facilitate tracking the ratings in subsequent years. In addition, a quantifiable legislative ratings system could serve as a base to investigate correlations between changes in state laws and measures of access to tobacco by young people- for example, based on the percentage of successful underage purchases. The system also has the potential to provide the framework for the more complicated examination of the relationship between changes in youth access laws and changes in smoking prevalence by young people, although the limitations in ecological data of this kind are recognised. 
Interpretation of these ratings of state laws also must consider the range of state and local regulatory options available and the increasing use of non-legislative state policy approaches. The ratings here reflect state laws only. State policy initiatives, such as executive orders and regulations, as well as local ordinances, were not rated, although these rating criteria could, with some minor modification, be applied to such initiatives.

An item on packaging was included in this rating system, giving points to those states that have limited the out-of-package sale of cigarettes as part of their youth access provisions. ${ }^{20}{ }^{36}$ In addition, it should be noted that state laws may ban cigarette sales that are not in a package marked with a tax stamp. This type of provision is not reflected in this youth access rating system.

The ratings here gave credit for having a statewide enforcement mechanism if a state agency had been designated regarding compliance with youth access laws. As of 1996, various state entities were empowered to oversee enforcement of these laws, including departments of finance, safety, alcohol, and public health. However, the question of whether particular state agencies can successfully implement youth access laws is beyond the scope of this analysis. Moreover, in some states, licensing enforcement may fall under a state's vendor/licensure laws, which are not reflected here.

Expectations concerning the impact of state laws on youth access to tobacco must be considered in the context of two issues. First, the ratings system does not address the extent to which laws are implemented and enforced in each state. We recognize that strong legislation and carefully constructed statutory language are necessary, but not sufficient by themselves, to ensure compliance with recommended public health policy. Second, the relationship between state tobacco policy and the subsequent use of tobacco products by young people is not addressed here. These components were beyond the scope of the current analysis, but may well suggest the course for future analysis.

\section{Conclusion}

Although all states have laws addressing youth access to tobacco, the analysis presented here reveals that, as of 1996, progress towards meeting health policy targets is slow, and state legislation that preempts local tobacco regulation is increasingly common. At the same time, young people are able to purchase cigarettes, and teenage smoking rates have been increasing in the 1990s. Such data suggest the need for states to undertake a critical examination of relevant laws and their enforcement. In addition, we hope that the ratings system may provide a base for future studies that correlate changes in state tobacco control laws with youth access to tobacco, smoking prevalence, and related cancer control measures.

Policy can play an important role in addressing the public health problem of tobacco use among young people, but simply having a law on the books is not enough. Laws must focus adequately on the various avenues that facilitate youth access to tobacco and the mechanisms used to weaken policy restrictions, and they must provide a framework for effective enforcement. The overall impact will depend on the specifics of the laws that are in place and on how these laws are implemented and enforced.

The contributions herein of MHA and SBG were done principally while at the National Cancer Institute, National Institutes of Health. The contributions herein of AR are hers as an author and may not necessarily reflect the opinions, official policy, or position of the Substance Abuse and Mental Health Services Administration, Public Health Service, US Department of Health and Human Services. AR is now at the National Institute on Drug Abuse, National Institutes of Health. The authors acknowledge Liza A Fues and Jamie F Chriqui of The MayaTech Corporation for their significant contribution to the legislative and data analysis required for this evaluation.

1 US Department of Health and Human Services. The health consequences of smoking: cancer. A report of the Surgeon General, 1982. Bethesda, Maryland: Public Health Service, Office on Smoking and Health, 1982 (DHHS Publication No (PHS) 82-50179.)

2 US Department of Health and Human Services. Reducing the health consequences of smoking: 25 years of progress. A report of the Surgeon General, 1989. Rockville, Maryland: Public Health Service, Centers for Disease Control, Office on Smoking and Hea

3 US Centers for Disease Control and Prevention. Cigarette smoking-attributable mortality and years of potential life lost-United States, 1990. MMWR 1993;42:645-9.

4 Johnston LD, O'Malley PM, Bachman JG. National survey results on drug use from the Monitoring the Future Study, 1975-1993. Vol I: secondary school students. Rockville, Maryland: US Department of Health and Human Services, Public Health Service, National Institutes of Health, National Institute on Drug Abuse, 1994. (NIH Publication No 94-3809.)

5 Glynn TJ, Manley MW, Gerlach KK, et al. Public health approaches to tobacco use prevention and cessation in the approaches to tobacco use prevention and cessat.

6 University of Michigan. Monitoring the Future Study press release. Ann Arbor, Michigan: University of Michigan, News and Information Services, 1997.

7 US Department of Health and Human Services. Preventing tobacco use among young people. A report of the Surgeon General, 1994. Atlanta, Georgia: Public Health Service, Centers for Disease Control and Prevention, Office on Smoking and Health, 1994. (US Government Printing Office Publication No S/N 017-001-00491-0.)

8 Kessler DA. Nicotine addiction in young people. $N$ Engl f Med 1995;333:186-9.

9 Giovino GA, Henningfield JE, Tomar SL, et al. Epidemiology of tobacco use and dependence. Epidemiol Rev 1995; 17:48-65.

10 Shopland DR, Haenlein M. Reducing lung cancer through smoking prevention and control. In: Samet JM, editor. Epidemiology of
1994:437-64.

11 US Department of Health and Human Services. Strategies to control tobacco use in the United States: a blueprint for public health action in the 1990s. Bethesda, Maryland: Public Health Service, National Institutes of Health, National Cancer Institute, 1991. (NIH Publication No 92-3316.)

2 US Department of Health and Human Services. Tobaccocontrol activities in the United States, 1992-1993: biennial report to Congress. Atlanta, Georgia: Public Health Service, Centers for Disease Control and Prevention, 1995.

13 Shelton DM, Alciati MH, Chang MM, et al. State laws on tobacco control-United States, 1995 (CDC Surveillance Summaries). MMWR 1995 (Nov 3);44(SS-6).

14 DiFranza JR, Norwood BD, Garner DW, et al. Legislative

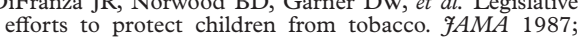
257:3387-9.

15 Jason LA, Ji PY, Anes MD, et al. Active enforcement of cigarette control laws in the prevention of cigarette sales to minors. FAMA 1991;266:3159-61.

16 Rigotti NA, DiFranza JR, Chang Y, et al. The effect of enforcing tobacco-sales laws on adolescents' access to tobacco and smoking behavior. $N$ Engl $f$ Med 1997; 337:1044-51

17 Siegel M, Carol J, Jordon J, et al. Pre-emption in tobacco control. FAMA 1997;278: 858-63.

18 US Department of Health and Human Services. Healthy people 2000: midcourse review and 1995 revisions. Hyattsville, Maryland: Public Health Service, Centers for Disease Control and Prevention, National Center for Health Statistics, 1996.

19 American Public Health Association. Public policy statements of the American Public Health Association: 1948-1994 collection. Washington, DC: American Public Health Association, 1995. 
20 Institute of Medicine. Growing up tobacco free: preventing nicotine addiction in children and youths. Lynch BS, Bonnie RJ, eds. Washington, DC: National Academy Press, 1994:214-5

21 Wildey MB, Woodruff SI, Pampalone SZ, et al. Self-service sale of tobacco: how it contributes to youth access. Tobacco Control 1995;4:355-61.

22 Cummings KM, Pechacek T, Shopland D. The illegal sale of cigarettes to US minors: estimates by state. Am $\mathcal{F}$ Public Health 1994;84:300-2.

23 US Centers for Disease Control and Prevention. Tobacco use and usual source of cigarettes among high school

24 Davis RM, Jason LA. The distribution of free cigarette samples to minors. Am f Prev Med 1988;4:21-6.

25 No sale: youth, tobacco and responsible retailing. Findings and recommendations of a working group of state attorneys general. December 1994.

26 US Department of Health and Human Services. Youth access to tobacco. Washington, DC: Office of the Inspector General, 1992. (Publication No OEI-02-91.)

27 Association of State and Territorial Health Officials Committee on Tobacco or Health. Responses to the Synar implementation Tobacco or Health. Responses to the Synar implementation survey. Washington, DC: A

28 Sylvester K. The tobacco industry will walk a mile to stop an anti-smoking law. Governing 1989 May:34-40.

29 Jordan J, Pertschuk M, Carol J. Preemption in tobacco control: history, current issues, and future concerns. Berkeley, California: California Wellness Foundation, 1994.

30 Conlisk E, Siegel M, Lengerich E, et al. The status of local smoking regulations in North Carolina following a state preemption bill. $\mathcal{F A M A}$ 1995;273:805-7.

31 Skolnick AA. Cancer converts tobacco lobbyist: Victor L Crawford goes on the record. FAMA 1995;274:199-202.

32 Davis RM. The ledger of tobacco control: is the cup half empty or half full? $¥ A M A 1996 ; 275: 1281-4$.

33 Jacobson PD, Wasserman J, Raube K. The politics of antismoking legislation. F Health Polit Policy Law 1993; 18:787-819.

34 Public Law 102-321. ADAMHA Reorganization Act 102nd Congress, 2nd Session, S 1306, 1992 (June 3); 45 CFR 96, 61. Federal Register 1996 Jan 19:1492-509.

35 US Department of Health and Human Services, Food and Drug Administration. Regulations restricting the sale and distribution of cigarettes and smokeless tobacco to protect children and adolescents: final rule. Federal Register 1996; 61:44396-5318.

36 Klonoff EA, Fritz JM, Landrine $\mathrm{H}$, et al. The problem and sociocultural context of single-cigarette sales. $\mathcal{F} A M A$ 1994;271:618-20.

\section{Appendix: Decision criteria for rating state youth access laws}

Notes

(a) For each item, +4 represents the target provision.

(b) For each item, state preemption of stricter local ordinances reduces the rating by two points (with a minimum of 0 ).

\section{Minimum age}

+5 Same as target (+4) below, but advances the minimum age requirement above the target age of 18 years

+4 Prohibits the sale or distribution of any tobacco products to persons under 18 years of age through any sales or distribution outlet and a warning sign is required at point of purchase with specific penalty for failing to post a sign

+3 Meets the target age, but does not require signs to be posted, or there is no specific penalty for failure to post a sign, or both

0 No provision

\section{Packaging}

+4 Prohibits all cigarette sales other than in a sealed package conforming to federal labelling requirements

+3 Meets the target requirement, but provides for minimal exceptions (for example, shops selling tobacco exclusively)

0 No provision
3 Clerk intervention

+4 Prohibits access to or purchase of tobacco products without the intervention of a sales clerk

+3 Meets the target requirement, but provides a specified exception, such as carton sales 0 No provision

\section{Photographic identification}

+5 Same as target (+4) below, but advances the minimum age of appearance above the target age of 21 years

+4 Requires merchants to request photographic identification for people who appear to be under 21 years of age

+3 Photographic identification required, but provision does not meet the target age of appearance of 21 years

+2 Photographic identification required, but provision is not specific concerning age requirement for showing identification

+1 Identification required for those who appear to be under 21 years of age, but does not specify photographic identification

0 No provision

5 Vending machines

+4 Total ban on sale of all tobacco products through vending machines in all locations

+3 Restricts the location of vending machines to adult-only locations, with supervision or requirement that machine(s) be placed at least 20 feet $(6.1 \mathrm{~m})$ from any entry

+2 Restricts the location of vending machines to adult-only locations (with no or partial supervision), or restricts the location of vending machines to adult-only locations with minimal exceptions and full supervision

+1 No location restrictions but vending machines in non-adult locations must be supervised (and/or have locking devices or tokens), or vending machines restricted to adult-only locations with minimal exceptions and no or partial supervision

0 No provision other than sales/distribution law, or a provision that specifies only minimal location restrictions and no or partial supervision

6 Free distribution

+5 Same as target (+4) below, plus a specific ban on sampling through the mail

+4 Total ban on distribution of free tobacco samples, coupons for free samples, or rebates

+3 Distribution of free tobacco samples, coupons for free samples, or rebates prohibited in any locations accessible to minors

+2 Total ban on distribution of samples of either cigarettes or smokeless tobacco products, but not both; or ban on distribution of samples of all tobacco products with minimal exceptions for locations not generally accessible to minors

+1 Selected sampling location restrictions (such as playgrounds, schools); or sampling location restrictions on either 
cigarettes and smokeless tobacco products, but not both

0 No restrictions on sampling other than the law prohibiting sales/distribution to minors

7 Graduated penalties

+4 Establishes a system of graduated penalties or fines applicable to all youth access laws, to be levied within three years, plus possibility of suspension or revocation of a required tobacco retail license for repeated sales to minors

+3 Graduated penalties or fines applicable to all youth access laws, to be levied within three years, but no possibility of licence suspension or revocation

+2 Set penalty for all or some youth access laws, or exceptions that limit enforcement, or both

+1 Any of above, but a requirement that penalties or fines are delayed beyond three years

0 None of the above, or any of the above with an intent requirement-for example, "knowing" violation-or affirmative defence(s) based on only minimal (or possibly minimal) compliance with youth access law(s)

\section{Random inspections}

+4 Establishes random, unannounced inspections of retailers as part of the enforcement mechanism, using underage buyers for the purpose of identifying violators, and does not prohibit other use of minors to test compliance

+2 Requires inspections, but with limitations

0 No provision, or any provision that specifically prohibits the participation of underage buyers in enforcement efforts

\section{Statewide enforcement}

+4 Establishes a clearly designated statewide enforcement authority for sales

+2 Some enforcement authority, other than statewide, is designated

0 No provision

\section{Tobacco Control <http://www.tobaccocontrol.com>}

Visitors to the world wide web can now access Tobacco Control either through the BMJ Publishing Group's home page <http://www.bmj.com> or directly by using its individual URL < http://www.tobaccocontrol.com>. There they will find the following.

- Current contents list for the journal

- Contents lists of previous issues

- Members of the editorial board

- Subscribers' information

- Instructions for authors

- Details of reprint services.

There is also a longer version of the "Play It Again" section of Tobacco Control that was published in the Winter 1996 issue of the journal, cataloguing tobacco-related quotes made during the 1996 United States presidential campaign.

A hotlink gives access to:

- BMJ Publishing Group home page

- British Medical Association web site

- Online books catalogue

- BMJ Publishing Group books

The web site is at a preliminary stage and there are plans to develop it into a more sophisticated site. Suggestions from visitors about features they would like to see are welcomed. They can be left via the opening page of the BMJ Publishing Group site or, alternatively, via the journal page, through "About this site". 